\title{
Reactive Lymphocytes to Leukocytes Ratio Measurement
}

National Cancer Institute

\section{Source}

National Cancer Institute. Reactive Lymphocytes to Leukocytes Ratio Measurement. NCI Thesaurus. Code C158230.

The determination of the ratio of reactive lymphocytes compared to total leukocytes present in a sample. The measurement may be expressed as a ratio or percentage. 